\title{
TEACHING WRITING BASED ON CORPUS-BASED LINGUISTIC RESEARCH
}

\author{
Michael P. Jordan
}

\section{Background}

Linguistics ("the scientific study of language"--Lyons, 1968) encompasses a broad spectrum of studies. These include socio- and psycho-linguistics, comparative studies and historical linguistics, morphology, syntax, phonology and phonetics, semantics and semiology, stylistics, pragmatics and discourse analysis. The work of many linguists is primarily involved with the search for an explanatory theory of language that integrates the major elements of clausal syntax, morphology (parts of words) and semantics--essentially the "grammar" of language. Although many such grammars have been devised and refined and they can each, in their own way, provide valuable insights to teachers of writing, there is little evidence that they currently have the potential to be of great practical value for our purposes. A noteworthy exception is the application of tagmemic principles to rhetoric jy Young, Becker and Pike (1970).

A look at most linguistics books will leave most teachers of expository writing totally bewildered with what they might perceive as unnecessarily narrow and complicated analysis. This depth of study, however, is necessary for the linguist's aims, and we have no right to criticize it for failing to meet our needs. Indeed many linguists would regard any "application." of their work to anything other than teaching other linguists as contrary to their philosophical intent. Such a view is perfectly defensible for linguists working clearly within the humanities. Their aim is to explore human articulation in a philosophical/ theoretical way with little reference to language use in communicative contexts.

Other linguistic work, however, is better classified as a social science (or better still a "human science"), as it studies the way we actually use language to express ourselves. This sort of work is of potential use by teachers of writing--either directly or indirectly--and its study is likely to prove of more practical value than the humanistic work. The difference depends on the linguist's approach. Work based on examples made up by the linguist out of context is unlikely to yield results of practical value to writing teachers. In contrast, work describing examples of actual language use is likely to have greater pedagogical potential. The present paradigm of technical writing appears to have evolved through emulation of the former approach rather than the latter, with the result that our discipline currently lacks the sound language-based theoretical framework necessary for scholastic respectability. This article seeks to introduce and encourage work $=0$ remedy that deficiency. 


\section{The Aims of Corpus-Based Analysis}

One linguistic research approach involves first the collection and classification of many examples of published writing in a defined area of study, and then their analysis and description within an established or developing theoretical framework. This approach perhaps comes closest to the ideal linguistic aim of being "scientific" as expressed by Lyons. Like any scientist, the linguist can have a hypothes is to test or simply an area to investigate. The work is done by collecting primary data followed by its classification, analysis and interpretation.

A recent discussion (Jordan, 1986a) explains and exemplifies this approach to language study, seeking to validate an established linguistic finding through duplication of an "experiment" in the scientific tradition. That discussion also demonstrates the value of using collected examples of actual language use (a "corpus") as the basis for a reasonably-objective analysis free from the linguist's subconscious biases. Although the emphasis there necessarily deals with a very small topic as an example, the principle applies equaliy to many topics of vital interest to teachers of technical writing.

The work of "corpus-based" linguists is characterized by their insistence that all language claims must be thoroughly validated by detailed analysis of examples of language in context--the primary data. In this philosophy, there is no room for the traditional rejection of such useful devices as anticipatory It, existential There, dangling participles, signals of doubt, and author evaluations (e.g. Hopefully). Nor is there uncritical acceptance of traditional rhetorical concepts such as those involved with topic sentences, "vague reference," classical logic and argument, and paragraph unity. The linguist seeks to discover what skilled writers do and how and when they do it, rather than accepting and repackaging what traditional wisdom tells us they should do. This does not mean that the established impressionistic "rules" of effective writing are ignored or rejected; but it does mean they must all eventually be subject to critical scrutiny with a view to their refinement as concrete principles of language, or their rejection.

The linguist, however, is much more interested in discovering systems of language than in sniping at the half-truths of language use. The linguist's aim is essentialiy positive rather than negative. This is also seen in what the linguist has to offer the technical writing teacher: not rules that limit or prohibit uses of certain structures, words or techniques, but systems of language use for students to learn and apply (Jordan, 1986d).

\section{Origin and Developments of the Approach}

Development of systems of textual continuity and meaning through multi-example corpus analysis was pioneered by Dr. Eugene Winter, who 
used the approach for both research and teaching in Trondheim, Norway and The Hatfield Polytechnic, England. Based on his earlier experience with corpus studies in the landmark OSTI program (Huddleston et al, 1968; Winter, 1968), and his further analysis of inter-clausal connection in technical English (1971), his analytical and teaching techniques were fully justified and exemplified in his doctoral work on the clause relations of English (1974). Winter's teaching handbook (1976), unfortunately not widely available, explains to teachers of technical writing how to use selected examples of published writing in various ways to teach structure and continuity-signaling; and this was followed by a rigorous linguistic and pedagogical explanation of clause relations and their signaling devices (1977). More recently, he has demonstrated the need for contextual language analysis (1982) and discussed many concepts of technical problem-solving analysis and writing (Hoey and Winter, 1986).

Hoey's development of Winter's work and his own advances (1979) convincingly demonstrate the power of analysis "On the Surface of Discourse" (1983), again using examples of published texts. Jordan's related work, while being centrally concerned with technical writing $(1980,1981,1984 a, 1985 a, 1986 b)$, has also been applied to teaching in the two-year college, ESL, business communication and rhetoric for freshman English (1984b). More significant scholastically, the work has faced the critical review of linguists in several recent publications.

The work so far has concentrated on the chain of continuity in description and other genres (lexical cohesion), structure and meaning in problem-solution-evaluation texts, and relations of meaning between clauses and sentences (clause relations). A discussion of these three areas of study, together with a detailed bibliography, is available elsewhere (Jodan 1986c).

\section{From Applied Research to Teaching}

Recent work (Davies, 1986; Jordan 1986d/e/f) has started to show the usefulness of established language systems to the practical teaching of technical writing. Now that many more linguists are taking an active interest in describing the structures and continuity of paragraphs and larger texts, we are beginning to build a solid and sufficientiy broad basis of research findings on which meaningful units of instructional material can be developed. Yet few linguists are interested in applying the research to the teaching of writing, leaving the opportunity to language-minded writing teachers.

The real challenge of teaching based on linguistically derived principles of language is that it requires a teaching philosophy consistent with the linguist's necessarily inquisitive approach to language exploration and study. It is so much easier to appear to students as a "communications expert" able to give definitive rulings on what is "correct" and what is not. The teaching of "rules" of writing 
performance and the teaching of process rather than product and process can both be effective. However, they lack the detailed intel lectual exploration of real language as a vital part of practical language education.

The need for teachers of writing to have some knowledge of applied linguistics is likely to intensify. As academics, we have a responsibility to rise above the necessarily practical, judgmental approach of technical writers and editors. With a sound linguistic base, teachers can now do more than tell students what not to do and then correct them when they do it. It is now possible to describe, in detail, systems and techniques used by skilled writers and editors, and to help and encourage students to emulate them. As more scholastically-rninded language scholars join our ranks, and as scholarly standards continue to rise, there should be growing pressures to apply minimum linguistic standards to the substance of what we teach. That in turn should result in greater use of examples of actual language use for both research and teaching.

\section{Using Indexes for Future Development}

Even quite short examples of actual language use contain instances of a large number of language features. It is this richness of language that could cause many teachers to prefer not to analyze examples in depth for fear of being faced with questions outside the restricted paradigm of traditional knowledge. However, for those who feel able to explore language with their students and to lead them in an exciting learning process, real examples provide the basis not only for discussing the major features being analyzed, but aiso as a constant stimulus for side-discussions of almost any element of written English or French.

This broad teaching (and research) potential has already led to compilation of language features in indexes (Jordan 1984a/b, 1986c), which could be computerized for even wider application. An exhaustive analysis of all language features in even the briefest example would take far too long, and would distract readers from the main point of the example. Indexing enables all the useful features of the examples to be noted (and made available for detailed study or research) while freeing the main discussion from distracting, though valuable, comment. As an example, the main discussion in Jordan $1984 \mathrm{~b}$ concerns major information structures (with problems, solutions, evaluations, etc.), but instances of many other topics (e.g., logic, doubt, informality) and selected key words (e.g., but, this, although) throughout the examples are listed in indexes. These have been called a "new kind of semantic thesaurus" by Masterman (1985).

Future texts dealing with more general aspects of writing could index such topics as punctuation, conciseness, continuity systems, style, and word choice for review purposes or advanced study. Such indexes could be computerized, and software developed to allow instant 
retrieval of example after example of a certain feature (e.g., semicolons, or restrictive relative clauses). In this way students can work out the language systems themselves. That, after all, is how we learned language in the first place.

\section{Final Remarks}

The approach outlined here is just one of many ways that linguists go about their work. It is, however, a method that should be intuitively acceptable to those with an appreciation for the clear validation of a thesis from primary data, and to those with an understanding of scientific tradition. Because of the nature of our work, most of us can claim some understanding of both concepts.

Use of examples of actual language use is also a demonstrably sound method already applied to technical writing as well as to other communications studies and to linguistic analysis. Although the work available so far could still be regarded as largely embryonic, it has already provided detailed analysis of several important topics in technical writing. And the advantages of using research corpus examples as illustrations during teaching is an obvious and very real benefit for researchers.

The research technique and related work described here, by relying on analysis of primary data, results in systematic descriptions of writers' skills to high levels of validity. This confidence is well expressed by Hoey: "We are acutely conscious of what a paltry beginning this book is, compared with the work still to be done. Our only consolation is that this book is a shanty-town built on rock rather than a palace built on sand". (1983, p. 188). From these small beginnings could eventually emerge an integrated theory of textual cohesion (Jordan, 1985b) of great theoretical and practical value to teachers of technical writing.

\section{REFERENCES}

Davies, N. 1986. "Using Case Studies to Teach Report Writing - A Pedagogical Analysis," Technostyle, 5(1), pp. 1-11.

Hoey, M.P. 1979. "Signalling in Discourse", Discourse Analysis Monographs No. 6, Birmingham University Press, England.

Hoey, M.P. 1983. On the Surface of Discourse, London: George Allen and Unwin.

Hoey, M.P. and Winter, E.0. 1986. in Functional Approaches to Writing: Research Perspectives (B. Couture - ed.T, London: Frances Pinter. 
Huddleston, R.D., Hudson, R.A., Winter, E.0. and Henrici, A. 1968. "Sentence and Clause in Scientific English," OSTI Project No. 3050, University of London, England.

Jordan, M.P. 1980. "Short Texts to Explain Problem-Solution Structures - and Vice Versa," Instructional Science, 9, pp. 221-52. (NCTE best research article in technical and scientific writing, 1982).

Jordan, M.P. 1981. "Some Associated Nominals in Technical Writing," Journal of Technical Writing and Communication, 11(3).

Jordan, M.P. 1984a. Fundamentals of Technical Description, Krieger (Award of Merit, STC Canadian Awards, 1985).

Jordan, M.P. 1984b. Rhetoric of Everyday English Texts, London: George Allen and Unwin.

Jordan, M.P. 1985a. "Clause-Relational Associated Nominals in Technical English", Technostyle 4(1), pp. 36-46.

Jordan, M.P. 1985b. "Towards an Integrated Theory of Textual Cohesion," Journal of the Midland Association for Linguistic Studies (UK), New Series, 10, pp. 9-40.

Jordan, M.P. 1986a. "Close Cohesion with do so - a linguistic experiment using a multi-example corpus," in Functional Approaches to Writing: Research Perspectives (B. Couture - ed.), London: Frances Pinter, ch. 2 .

Jordan, M.P. 1986b. "The Genre of Technical Description," The Technical Writing Teacher, 13(1), pp. 42-50.

Jordan, M.P. 1986c. "Co-Associative Lexical Cohesion in Promotional Literature," Journal of Technical Writing and Communication, 16(1/2), pp. 33-53.

Jordan, M.P. 1986d. "Applying Language Systems to the Teaching of Writing," The Technical Writing Teacher, Fall (special issue on linguistic applications to the teaching of technical writing - C. Todenhagen ed.).

Jordan, M.P. 1986e. "How to Plan and Write Problem-Solving Documents," in Solving Problems in Technical Writing, ( $L$. Beene and P. White - eds.), Oxford University Press.

Jordan, M.P. 1986f. "Using Nonfinite Clauses in Editing," The Technical Writing Teacher, exercise exchange, forthcoming.

Lyons, J. 1968. Introduction to Theoretical Linguistics, Cambridge University Press, p. 1 . 
Masterman, M. 1985. "A New Approach to Finding Large-Scale Information Structures of Texts," Language Monthly, February, pp. 23-24.

Winter, E.0. 1968. "Some Aspects of Cohesion," in Sentence and Clause in Scientific English, Report on "The Linguistic Properties of Scientific English", University College, London, England.

Winter, E.0. 1971. "Connection in Science Material: a proposition about the semantics of clause relations," Centre for Information on Language Teaching, Papers and Reports, No. 7, Centre for Information on Language Teaching and Research, British Association for Applied Linguistics, pp. 41-52.

Winter, E.0. 1974. "Replacement as a Function of Repetition," Ph.D. Thesis, University of London, England: University Microfilms $77-70036$.

Winter, E.0. 1976. "Fundamentals of Information Structure: pilot manual," The Hatfield Polytechnic, mimeographed.

Winter, E.0. 1977. "A Clause Relational Approach to English Texts: A study of some predictive lexical items in discourse," Instructional Science, 6(1), special issue, pp. 1-92.

Winter, E.0. 1982. Towards a Contextual Grammar of Englis?, London: George Allen and Unwin.

Young, R.E., Becker, A.L., and Pike, K.L. 1970. Rhetoric: Discovery and Change, New York: Harcourt, Brace, Jovanovich.

Michael Jordan is a Professional Engineer and Professional Administrator with an interest in applied English language studies. Formerly a technical writer and publications manager, he has been teaching technical writing and English prose structures at Queen's University for the last 18 years. 